\title{
HASIL HUTAN BUKAN KAYU MADU SIALANG DI KABUPATEN KAMPAR (Studi Kasus : Kecamatan Kampar Kiri Tengah)
}

\author{
Eni Suhesti ${ }^{1}$, Hadinoto ${ }^{1}$ \\ 1Staf pengajar Fakultas Kehutanan Universitas Lancang Kuning \\ JIn. Yos Sudarso Km. 8 Rumbai Pekanbaru Riau \\ Telp./Fax. (0761) 54092 \\ Email : hesti1170@yahoo.co.id, hdinto@yahoo.co.id
}

\begin{abstract}
Non-Timber Forest Products (NTFPs) is part of a forest ecosystem that has an important role. One of NTFPs which have high economic value and is a source of livelihood of rural communities is often called wild honey or honey sialang. This study aims to: 1) Calculate the potential of the tree and the honey produced sialang 2) Knowing how to manage the honey sialang by society and the problems. Primary data was collected through interviews with respondents using the help of questioners. Data were analyzed descriptively. Potential production of honey from the beehive tree is quite large, each tree can sialang inhabited by about 30 colonies/nest, where the number has further decreased when compared to the time of the woods yet many are converted. In each tree each harvest can be produced approximately $150 \mathrm{~kg}$ of honey. Institutional managers honey sialang in the Sub-District of Middle Kampar Kiri is still very minimal. Honey gatherers farmers' organizations have not yet formed, there is only one indigenous group in the village of Penghidupan, whose members are people who are still there family relationship. There are 130 trees sialang and produced $19,500 \mathrm{~kg}$ of honey. Honey sialang management is still done traditionally.
\end{abstract}

Keywords: NTFPs, honey sialang, institutional 


\section{PENDAHULUAN}

Hasil Hutan Bukan Kayu (HHBK) merupakan bagian dari ekosistem hutan yang memiliki peranan yang beragam, baik terhadap lingkungan alam maupun terhadap kehidupan manusia. HHBK yang sudah biasa dimanfaatkan dan dikomersilkan diantaranya adalah cendana, gaharu, sagu, rotan, aren,sukun, bambu, sutera alam, jernang, kemenyan, kayu putih, aneka tanaman obat, minyak atsiri dan madu. Salah satu HHBK yang memiliki nilai ekonomi tinggi dan merupakan salah satu sumber pencaharian masyarakat pedesaan adalah madu hutan atau sering juga disebut madu sialang. Madu hutan dihasilkan oleh lebah madu Apis dorsata yang masih bersifat liar dan ganas dan biasanya bersarang di pohonpohon jenis tertentu yang disebut pohon sialang.

Eksistensi madu sialang saat ini semakin terancam dengan semakin tingginya laju perusakan hutan dan konversi lahan hutan untuk penggunaan lain. Penebangan pohon sialang dan jenis tanaman lainnya untuk diambil kayunya atau digunakan lahannya untuk hutan tanaman industri yang monokultur atau tanaman perkebunan. Kehidupan lebah madu Apis dorsata sangat tergantung pada keberadaan pohon sialang dan tanamantanaman lainnya sebagai sumber pakan.

Kabupaten

Kampar merupakan salah satu daerah di Propinsi Riau yang potensial sebagai penghasil madu sialang karena memiliki kawasan hutan yang luas. Beberapa daerah di Kabupaten Kampar terkenal sebagai penghasil madu sialang, diantaranya Kecamatan Kampar Kiri Hulu, Kecamatan Kampar Kiri Tengah, dan Kampar Kiri Hilir. Dalam penelitian ini kajian hanya dilakukan di Kecamatan Kampar 
Kiri Tengah, karena merupakan salah satu daerah yang belum memiliki data tentang potensi madu dan pohon sialang, padahal cukup banyak masyarakatnya bermata pencaharian sebagai petani madu. Penelitian ini bertujuan untuk : 1) Menghitung potensi pohon sialang dan madu yang dihasilkan di Kecamatan Kampar Kiri Tengah; 2) Mengetahui cara pengelolaan madu sialang oleh masyarakat Kampar Kiri Tengah dan permasalahannya.

\section{METODE}

\section{Waktu dan Lokasi Penelitian}

Penelitian ini dilakukan di Desa Penghidupan dan Desa Simalinyang, Kecamatan Kampar Kiri Tengah, Kabupaten Kampar. Alasan pemilihan kedua desa tersebut, karena di Kecamatan Kampar Kiri Tengah hanya di dua desa tersebut yang masih dilakukan pemungutan madu sialang secara rutin (informasi dari penyuluh kehutanan di Kecamatan Kampar Kiri Tengah). Waktu penelitian adalah bulan Januari sampai dengan bulan Maret 2015.

\section{Pengumpulan Data Sekunder}

Pengumpulan data dilakukan dengan penelusuran pustaka atau data yang ada di pemerintahan desa, kecamatan dan kabupaten. Data sekunder dikumpulkan dari berbagai sumber yang relevan dalam rentang waktu tertentu. Data yang dikumpulkan antara lain : kondisi biofisik lokasi penelitian dan data kondisi sosial ekonomi masyarakat.

\section{Pengumpulan Data Primer}

Data primer diperoleh melalui kegiatan survey dan observasi terhadap objek penelitian. Data yang diambil berupa profil petani madu sialang, kelembagaan dalam pengelolaan madu sialang, potensi hasil madu 
dan pohon sialang, serta permasalahan dan harapan petani madu dalam pengusahaan madu sialang.

\section{Metode Pengumpulan dan} Analisis Data

Data sekunder dikumpulkan dari kantor Desa, Kantor Camat dan Biro Pusat Statistik. Sedangkan data primer dikumpulkan melalui wawancara dengan responden menggunakan bantuan quisioner (terlampir). Penentuan responden dilakukan secara sengaja (purposive sampling) dengan kriteria tertentu, Responden yang akan diwawancarai adalah petani madu sialang di Desa Penghidupan dan Desa Simalinyang Kepala Desa, dan penyuluh pertanian/ kehutanan setempat.

Data yang diperoleh akan dianalisis secara deskriptif, yaitu penggambaran data yang diperoleh secara apa adanya, tanpa ada generalisasi (Irianto
2007). Data akan digambarkan melalui tabel atau grafik.

\section{HASIL DAN PEMBAHASAN}

\section{Kondisi Biofisik dan Sosial} Ekonomi Masyarakat

Penelitian ini dilakukan di Kecamatan Kampar Kiri Tengah yang terdiri dari 11 Desa, di mana 2 desa merupakan penghasil madu sialang, yaitu Desa Simalinyang dan

Desa

Penghidupan.

Observasi lapangan dan pengambilan responden dilakukan di dua desa tersebut, sedangkan data kondisi biofisik lapangan dan sosial ekonomi masyarakat secara umum diambil dari kondisi di Kecamatan Kampar Kiri Tengah (Kampar Dalam Angka 2013). Wilayah Kecamatan ini memiliki topografi datar dengan ketinggian 51 mdpl. Curah hujan rata-rata tahunan sebanyak $244 \mathrm{~mm} /$ tahun. Dengan kondisi faktor iklim tersebut, maka lokasi penelitian ini termasuk ke dalam kategori iklim 
tipe A, yaitu iklim hujan tropis berdasarkan klasifikasi Koppen (Anonim 2015). Ciri-ciri wilayah beriklim tipe $A$ ini adalah temperature bulanan rata-rata lebih dari $18^{\circ} \mathrm{C}$. Dengan curah hujan bulanan lebih dari $60 \mathrm{~mm}$. Daerah-daerah yang memiliki iklim tipe A ini biasanya ditumbuhi oleh pepohonan dengan tajuk yang lebat dan tinggi dengan keanekaragaman yang tinggi pula.

Luas wilayah lebih kurang $50.681,60 \mathrm{Ha}$ dan seluas $3.463,8$ $\mathrm{Ha}$ di antaranya adalah hutan Negara (Kampar Dalam Angka 2013). Jenis dan luas masingmasing penggunaan lahan yaitu, hutan seluas $3.463,8 \mathrm{Ha}$, tegalan/kebun seluas $35.635,5$ $\mathrm{Ha}$, pekarangan, bangunan dan pemukiman seluas 2.649,75 $\mathrm{Ha}$, dan penggunaan lainnya seluas 8.932,3 Ha.

\section{Penduduk}

Desa

Penghidupan

dan Desa

Simalinyang didominasi oleh suku
Melayu dengan pekerjaan sebagian besar masyarakat adalah sebagai petani karet dan kelapa sawit atau nelayan. Sedangkan agama yang dianut adalah $100 \%$ Islam. Jumlah penduduk di Kecamatan Kampar Kiri Tengah adalah 25.537 jiwa yang terdiri dari 13.296 orang lakilaki dan 12.241 orang perempuan.

\section{Berdasarkan} hasil pengamatan, jenis-jenis tanaman yang tumbuh di lokasi penelitian terdiri dari tanaman kehutanan seperti akasia (Acacia mangium), keruing (Dipterocarpus trinervis), rengas (Gluta renghas), cempedak air (Artocarpus sp), nangka (Artocarpus integra), durian (Durio zibetinus), manga (Mangifera indica), manggis (Garcinia mangostana), dan lainlain. Sedangkan tanamana perkebunan terdiri dari kelapa (Cocos nucifera), karet (Hevea brasiliensis), dan kelapa sawit (Elaeis sp). Selain tanaman 
kehutanan dan tanaman perkebunan tersebut, di lokasi penelitian juga terdapat tanaman palawija dan banyak jenis rumputrumputan.

\section{Profil Responden}

Madu sialang adalah madu yang dihasilkan oleh lebah jenis Apis dorsata, yaitu suatu jenis lebah madu yang sifatnya masih liar dan ganas, sehingga belum berhasil

dibudidayakan.

Masyarakat sekitar hutan memanfaatkan madu sialang atau yang sering disebut juga madu hutan dengan

cara

mengumpulkannya dari sarangsarang lebah yang terdapat pada pohon-pohon yang besar dan tinggi yang sering diistilahkan sebagai pohon sialang. Para petani yang yang pekerjaannya mengumpulkan madu sialang ini disebut sebagai petani pengumpul madu sialang.
Dalam penelitian ini yang menjadi responden utama dalam pengumpulan data adalah para petani pengumpul madu sialang, karena mereka adalah pelaku utama dalam pengelolaan madu sialang yang sangat mengetahui tentang potensi madu sialang dan permasalahan-permasalahannya.

Selain terhadap petani pengumpul madu, wawancara juga dilakukan terhadap kepala desa dan petugas penyuluh pertanian.

\section{Potensi Pohon dan Madu} Sialang di Kecamatan Kampar Kiri Tengah

Seperti yang telah disebutkan di atas, bahwa lokasi yang selalu di datangi lebah madu jenis Apis dorsata untuk bersarang dan menetap dalam jumlah yang banyak di Kecamatan Kampar Kiri Tengah hanyalah Desa Penghidupan dan Desa Simalinyang. Dipilihnya dua desa tersebut oleh lebah madu pasti karena ada alasannya. Di antara 
alasan tersebut kemungkinan karena di dua desa tersebut masih terdapat pohon-pohon yang memiliki karakter yang disukai oleh lebah madu untuk bersarang. Menurut Hadisoesilo dan Kuntadi (2007) pohon yang dihuni agregasi lebah hutan biasanya adalah pohon yang menjulang tinggi dengan tajuk yang tidak terlalu padat dan percabangan yang relatif terbuka. Kulit pohon biasanya relatif bersih dan halus. Lebah hutan banyak dijumpai bersarang di cabang pohon yang diameternya bervariasi dari 5 hingga $100 \mathrm{~cm}$ dengan sudut kemiringan yang disukai sekitar $25^{\circ}-35^{\circ}$. Pohon dengan karakter demikian disebut masyarakat sebagai pohon sialang.

Masyarakat

Penghidupan

dan

Desa Simalinyang sangat menjaga pohon silang tersebut dan tidak mau menebangnya karena mereka sangat menyadari potensi hasil besar yang akan mereka peroleh dari hasil lebah yang bersarang di pohon tersebut. Saat ini jumlah pohon sialang yang masih terdapat di Desa Penghidupan sekitar 80 batang dan di Desa Simalinyang sekitar 50 batang (Hasil wawancara 2014). Jenis-jenis pohon sialang tersebut terdiri dari pohon rengas (Gluta renghas), keruing (Dipterocarpus trinervis), dan cempedak air (Artocarpus sp).

Potensi produksi madu dari pohon sialang cukup besar, menurut petani pengumpul madu yang diwawancarai, pada kondisi saat setiap pohon sialang dapat dihuni oleh sekitar 30 koloni /sarang, di mana jumlah tersebut sudah jauh menurun bila dibandingkan dengan pada waktu hutan belum banyak yang dikonversi. Dalam setiap pohon setiap kali panen dapat dihasilkan lebih kurang $150 \mathrm{Kg}$ madu. Waktu panen biasanya sekitar 3 bulan 
sekali dalam kondisi tanamam Tengah disajikan pada Tabel 2 sumber pakan terdapat dalam berikut ini. jumlah banyak. Potensi Madu sialang di Kecamatan Kampar Kiri

Tabel 2. Potensi Pohon sialang dan hasil madu di Kecamatan Kampar Kiri Tengah

\begin{tabular}{l|c|l|l}
\hline Nama Desa & $\begin{array}{c}\text { Jumlah } \\
\text { Pohon Sialang } \\
\text { (Batang) }\end{array}$ & $\begin{array}{r}\text { Potensi Hasil } \\
\text { Madu/sekali Panen (Kg) }\end{array}$ & \multicolumn{1}{c}{$\begin{array}{c}\text { Harga Jual Madu } \\
\text { (Rp) }\end{array}$} \\
\hline Penghidupan & 80 & $150 \mathrm{Kg} \times 80=12.000 \mathrm{~kg}$ & $\begin{array}{l}\text { @p.60.000 } \\
12.000 \times 60.000 \\
\text { Rp.720.000.000,- }\end{array}$ \\
\hline Simalinyang & 50 & $150 \times 50=7.500$ & $\begin{array}{l}\text { @Rp.60.000,- } \\
7.500 \times 60.000= \\
\text { Rp. } 450.000 .000,-\end{array}$ \\
\hline Jumlah & 130 & $19.500 \mathbf{~ k g}$ & Rp. 1.170.000.000,- \\
\hline
\end{tabular}

Sumber : Hasil wawancara (2015).

Potensi ekonomi hasil madu sialang di Kecamatan Kampar Kiri Tengah ini cukup besar. Hasil penjualan madu dari dua desa tersebut mencapai Rp. 1.170.000.000,-. Hasil demikian saat ini sudah jauh berkurang bila dibandingkan dengan saat kondisi hutan di sekitar desa-desa tersebut masih dalam kondisi asli. Pada saat itu jumlah koloni madu pada setiap pohon sialang bisa mencapai ratusan koloni.
Kelembagaan, Permasalahan dan Harapan dalam Pengelolaan Madu Sialang

Pengelolaan madu sialang di Kecamatan Kampar Kiri Tengah masih dilakukan secara tradisional, di mana kepemilikan pohon sialang berlangsung secara turun-temurun. Cara pemanenan madu dilakukan dengan cara memanjat pohon sialang pada waktu malam hari dan dilakukan oleh pemanjat pohon yang sudah berpengalaman dan memiliki keahlian serta keberanian. 
Pemanjat pohon tersebut bukan warga asli dari Desa Penghidupan dan Desa Simalinyang, tetapi warga yang berasal dari Sumatera Barat dan Nias. Pemanen madu biasanya berkelompok dengan pembagian tugas tertentu. Proses memanen madu cukup sulit, sehingga pembagian hasil madu untuk pemanjat atau pemanen ini lebih besar dari pada si pemilik pohon sialang, yaitu $2 / 3$ bagian untuk pemanjat dan $1 / 3$ bagian untuk pemilik pohon. Biasanya pemilik pohon akan menjual bagian madunya kepada pemanen. Selanjutnya pemanen akan menjual madunya kepada pengumpul besar untuk diolah lebih lanjut atau langsung dijual ke konsumen atau diekspor ke luar negeri.

Kelembagaan pengelola madu sialang di Kecamatan Kampar Kiri Tengah ini masih sangat minim. Organisasi petani pengumpul madu belum terbentuk, hanya ada satu kelompok adat yang berada di Desa Penghidupan, di mana anggotanya adalah masyarakat yang masih ada hubungan kelurga. Tidak seperti di kecamatan tetangganya yaitu, Kecamatan Gunung Sahilan dan Kecamatan Kampar Kiri Hilir, dimana pengelolaan madu sialang sudah mendapat bantuan dari LSM WWF dan Dinas Kehutanan, di Kecamatan Kampar Kiri Tengah ini belum ada bantuan dari pihakpihak lain.

\section{KESIMPULAN DAN SARAN Kesimpulan}

Berdasar pada hasil penelitian dapat disimpulkan sebagai berikut 1. Terdapat 130 batang pohon sialang ( 80 batang di Desa Penghidupan dan 50 batang di Desa Simalinyang) dan menghasilkan $19.500 \quad \mathrm{~kg}$ madu. 
2. Pengelolaan madu sialang masih dilakukan secara tradisional.

3. Permasalahan yang dihadapi antara lain: belum ada lembaga pengelola; hutan berkurang; belum ada bantuan dari pemerintah dan pihak lain; belum memiliki pemanjat dan masih terbatas pada madu saja.

\section{Saran}

1. Perlu dibentuk kelembagaan dalam mengelola madu sialang dalam rangka efektifitas dan efisiensi pengelolaan.

2. Perlu dibuat peraturan daerah sebagai payung hukum dalam perlindungan pohon sialang

3. Perlu dilakukan kegiatan pendampingan dari pemerintah dan pihak terkait lainnya.

\section{DAFTAR PUSTAKA}

Hadisoesilo S dan Kuntadi. 2007. Kearifan tradisional dalam "Budidaya" lebah hutan (Apis dorsata). Bogor: Departemen Kehutanan. Balitbang Hutan dan Konservasi Alam. CV.Dewi sri Jaya.

Kemententerian Tenaga Kerja dan Transmigrasi RI. 2014. Peraturan Menteri Tenaga Kerja dan Transmigrasi RI No. 1 tahun 2014

Kuntadi. 1993. Pengambilan madu lebah Apis dorsata di daerah Riau.

Komunikasi, Thun VIII (2) :1923. Balai Penelitian Kehutanan di Aek Nauli Sumatera Utara.

Menteri Kehutanan RI. 2007. Permenhut No.P.35/MenhutII/2007 tentang Hasil Hutan Bukan Kayu.

Moko H. 2008. Menggalakkan hasil hutan bukan kayu sebagai produk unggulan. INFORMASI TEKNIS Volume 6 No.2 September 2008.

Novandra A. dan Widnyana IM. 2013. Peluang pasar produk perlebahan 
Indonesia.

Atikel

disampaikan pada acara alih teknologi balai penelitian hasil hutan bukan kayu

Sudarmalik, Y Rochmayanto, dan Purnomo. 2006. Peranan beberapa hasil hutan bukan kayu (HHBK) di Riau dan Sumatera Barat. Prosiding Seminar Hasil Litbang Hasil Hutan 2006:199-219.

Thomas, S George, Varghese, dan Anita. 2009. Characteristics of trees used as rest sites by Apis dorsata (Hymenoptera, Apidae) in the Nilgiri Biosphere Reserve, India. Journal of Tropical Ecology 255 (Sept 2009) 559562. 